\title{
Under pressure: The right ventricular solution to a pulmonary vascular problem
}

\author{
Leora B. Balsam, MD, ${ }^{\mathrm{a}}$ and Abe DeAnda, Jr, $\mathrm{MD}^{\mathrm{b}}$
}

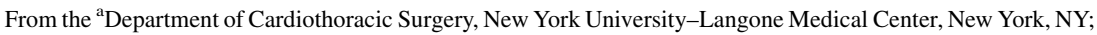
and ${ }^{\mathrm{b}}$ Division of Cardiovascular and Thoracic Surgery, University of Texas Medical Branch-Galveston, Galveston, Tex.

Disclosures: Authors have nothing to disclose with regard to commercial support.

Received for publication Aug 17, 2017; accepted for publication Aug 19, 2017; available ahead of print Sept 26, 2017.

Address for reprints: Leora B. Balsam, MD, Department of Cardiothoracic Surgery, NYU-Langone Medical Center, 530 First Ave Suite 9V, New York, NY 10016 (E-mail: leora.balsam@nyumc.org).

J Thorac Cardiovasc Surg 2017;154:2080-1

$0022-5223 / \$ 36.00$

Copyright (c) 2017 by The American Association for Thoracic Surgery

http://dx.doi.org/10.1016/j.jtcvs.2017.08.045
}

Functional capacity and survival in patients with chronic pulmonary hypertension are driven by the right ventricular (RV) response to pressure overload. A series of molecular, cellular, and structural changes occur that mark the balance between compensatory and maladaptive $\mathrm{RV}$ response. RV hypertrophy is an early adaptation to maintain cardiac output; however, it comes at the expense of increasing oxygen demand. Because elevated RV systolic pressure impairs flow in the right coronary artery during systole, increased coronary flow must occur at the level of the microcirculation, either through recruitment of unused capillary beds or through angiogenesis. When mismatch of oxygen delivery and workload occur, fibrosis, RV dysfunction and, ultimately, RV failure ensue.

The role of angiogenesis in RV adaptation to pressure overload had been studied in small animal models. Sutendra and colleagues ${ }^{1}$ identified a transition from compensated to decompensated RV function in the rat monocrotaline model of pulmonary hypertension, in which monocrotaline, an alkaloid derivative from the plant Crotalaria spectabilis, causes endothelial cell injury and pulmonary artery medial hypertrophy. The transition between the compensated and decompensated states is marked by decreased RV angiogenesis and decreased expression of angiogenic factors. RV capillary density is also reduced in the SU5146/chronic hypoxia model of pulmonary hypertension in rats, in which combined treatment with a vascular endothelial growth factor-receptor blocker (SU5146) and chronic hypoxia results in pulmonary hypertension and RV hypertrophy in the course of several weeks. ${ }^{2,3}$ Drake and associates ${ }^{4}$ described a molecular signature for compensated versus decompensated RV function in rat models of chronic severe pulmonary hypertension, with key differences in expression of genes related to angiogenesis, cell growth, and energy metabolism.

In this issue of the Journal, Noly and colleagues ${ }^{5}$ examine the relationship between mismatch angiogenesis

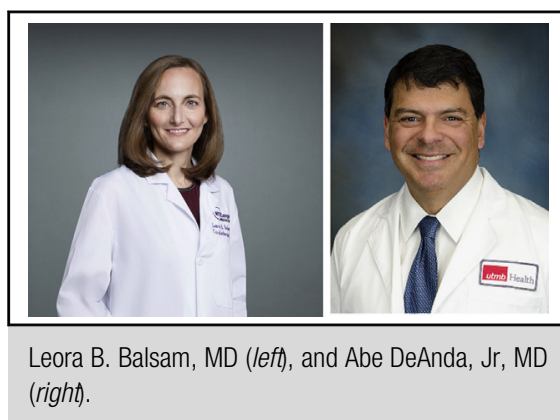

Central Message

Mismatch angiogenesis may be the cause of RV maladaptation to pressure overload. A new study examines the relationship between RV capillary density and RV stroke work in CTEPH and shunt models.

See Article page 2070. and RV dysfunction in 2 large-animal models of pulmonary pressure overload. ${ }^{5}$ The first is a porcine model of chronic thromboembolic pulmonary hypertension (CTEPH), created through ligation of the left main pulmonary artery and serial embolizations to the right lower lobe arteries with nonabsorbable glue. This model results in elevated pulmonary arterial pressures, elevated pulmonary vascular resistance, and histologic changes similar to human $\mathrm{CTEPH}$ during a 6- to 7-week period. ${ }^{6}$ The second is a porcine aortopulmonary shunt model, in which pulmonary hypertension develops more gradually, through a period of months. Noly and colleagues ${ }^{5}$ assessed RV function with echocardiography and right heart catheterization at baseline and after 20 weeks, and they found important differences in RV adaptation to pressure overload in the 2 models.

Taking a page from extensive studies of left ventricular mechanics and derived energetics, the relationship between pulmonary arterial elastance $\left(\mathrm{E}_{\mathrm{a}}\right)$ and $\mathrm{RV}\left(\mathrm{E}_{\mathrm{es}}\right)$ elastance (ie, RV-pulmonary artery coupling), demonstrates the trade-off between maximizing stroke work $\left(\mathrm{E}_{\mathrm{a}}=\mathrm{E}_{\mathrm{es}}\right)$ and ventricular efficiency $\left(\mathrm{E}_{\mathrm{es}}>\mathrm{E}_{\mathrm{a}}\right)$ in these models. ${ }^{7,8}$ The CTEPH model tends toward the former, whereas the shunt model tends toward the latter. The maximization of stroke work is at the expense of increased metabolic demand (and oxygen consumption). In addition, there was no significant change in right ventricular $E_{e s}$, so this would imply that $R V$ contractility was preserved in both models, whereas RV afterload $\left(\mathrm{E}_{\mathrm{a}}\right)$ increased significantly only in the CTEPH 
model. The maladaptation thus is the inability of the CTEPH RV myocardium to remodel to maintain efficiency, and this loss of efficiency reflects a decrease of total energy generated by the RV during systole that is converted into stroke work, resulting downstream in the observed decrease in venous oxygen saturation in the CTEPH model. As Noly and colleagues ${ }^{5}$ point out, the resultant tissue hypoxia may interfere with $\mathrm{RV}$ angiogenesis and lead to myocardial fibrosis. In keeping with this, they observed decreased RV capillary density in the CTEPH animals relative to the shunt animals.

Noly and colleagues ${ }^{5}$ propose that the ratio of capillary density and RV stroke work is a novel index that can be used to discriminate between the compensated and decompensated RV. Clinically, these authors and their colleagues have previously identified scoring systems derived from $\mathrm{RV}$ imaging and hemodynamic characteristics that are predictive of outcomes in patients with pulmonary arterial hypertension. ${ }^{9,10}$ One wonders what the comparative advantage of this new index may be. Moreover, for this index to have translational strength, a noninvasive methodology is needed to assess capillary density at serial time points, without the need for tissue biopsy of the myocardium.

This study raises the interesting question of whether therapeutic angiogenesis may improve RV adaptation to pressure overload. Medical treatments for pulmonary hypertension, including pulmonary vasodilators, may have limited efficacy in these patients, and surgical treatments, such as lung transplantation, may not be appropriate. Without reducing pulmonary hypertension, can the RV cellular, genetic, and energetic processes be manipulated to prolong its adaptive response? Fundamentally, it makes sense that increasing oxygen delivery through angiogenesis may help; as always, however, the devil will be in the details. Specifically, how can one directly target the RV with angiogenic factors? How much extra time in the compensated state will be gained with this strategy? What are the downstream effects of increased RV angiogenesis, including possible adverse effects? These questions merit continued careful study, and the animal models described provide a starting point.

\section{References}

1. Sutendra G, Dromparis P, Paulin R, Zervopoulos S, Haromy A, Nagendran J, et al. A metabolic remodeling in right ventricular hypertrophy is associated with decreased angiogenesis and a transition from a compensated to a decompensated state in pulmonary hypertension. J Mol Med. 2013;91:1315-27.

2. Ryan JJ, Archer SL. The right ventricle in pulmonary arterial hypertension: disorders of metabolism, angiogenesis, and adrenergic signaling in right ventricular failure. Circ Res. 2014;115:176-88.

3. Sakao S, Tatsumi K. The effects of antiangiogenic compound SU5416 in a rat model of pulmonary arterial hypertension. Respiration. 2011;81: 253-61.

4. Drake JI, Bogaard HJ, Mizuno S, Clifton B, Xie B, Gao Y, et al. Molecular signature of a right heart failure program in chronic severe pulmonary hypertension. Am J Respir Cell Mol Biol. 2011;45:1239-47.

5. Noly P-E, Haddad F, Arthur-Ataam J, Langer N, Dorfmüller P, Loisel F, et al. The importance of capillary density-stroke work mismatch for right ventricular adaptation to chronic pressure overload. J Thorac Cardiovasc Surg. 2017;154: 2070-9.

6. Mercier O, Tivane A, Dorfmüller P, de Perrot M, Raoux F, Decante B et al. Piglet model of chronic pulmonary hypertension. Pulm Circ. 2013;3:908-15

7. Sunagawa K, Maughan WL, Burkhoff D, Sagawa K. Left ventricular interaction with arterial load studied in isolated canine ventricle. Am J Physiol. 1983;245: H773-80.

8. Burkhoff D, Sagawa K. Ventricular efficiency predicted by an analytical model. Am J Physiol. 1986;250(6 Pt 2):R1021-7.

9. Haddad F, Spruijt OA, Denault AY, Mercier O, Brunner N, Furman D, et al. Right heart score for predicting outcome in idiopathic, familial, or drug- and-toxin associated pulmonary arterial hypertension. JACC Cardiovasc Imaging. 2015; 8:627-38.

10. Amsallem M, Sweatt AJ, Aymami MC, Kuznetsova T, Selej M, Lu H, et al. Righ heart end-systolic remodeling index strongly predicts outcomes in pulmonary arterial hypertension: comparison with validated models. Circ Cardiovasc Imag ing. 2017; 10:e005771. 